\section{Response availability, sex, academic ability, and academic achievement within a college population'}

\author{
ELIZABETH P. KIRCHNER, The Pennsyl- \\ vania State University, University Park, Pa. \\ 16802
}

Individual differences in response availability and their relationship to measures of intellectual abilities and achievement were studied in 81 college males and 85 college females. For males, response availability appears related to a slight degree to certain verbal skills; for females, there were no significant ability or achievement correlates of response availability.

While studies of the relationships of response availability or meaningfulness $(m$, Noble, 1952) and various dimensions of the stimulus word have yielded many consistent and robust findings (cf. Cramer, 1968, for a not been the case with investigations of subject variables as they relate to $m$. This latter domain seems characterized by less direct evidence, more complex relationships and fewer studies than are found in the area of $m$ and stimulus qualities. Regarding age and $m$, for example, Cramer (1968) states, " $m$ begins to increase at kindergartern level, increases to Grade 8 and perhaps beyond, then decreases from college to older adulthood." Investigations of sex differences in $m$ indicate that college females give more written responses than males (Matthews, 1965), but no sex differences obtain with 4 th, 6 th, and 8 th grade children (Shapiro, 1964). While creativity (Mednick, Mednick, \& Jung, 1964) and normality (Lester, 1960) are reported to be positively related to $m$, subject anxiety appears to be equivocal in its main effect on $m$ (Davids \& Erikson, 1955; Johnson \& Lim, 1964), although anxiety and grammatical class yield significant interaction effects (Johnson \& Lim, 1964). Finally, for personal values, and perhaps only for certain values, $m$ to stimuli representing different values is positively related to the endorsement of those values by the individual $S$ (Bousefield \& Samborski, 1955; Van Krevelen, 1956). Indeed, Deering (1963) and Laffal (1955) suggest that stimulus qualities, rather than subject variables, are the more forceful determinants of associative responses.

It is surprising, in view of the evident interest in exploring various individual thorough review of this subject), such has difference variables with regard to $m$, that studies reporting relationships between $m$ and ability and achievement measures are not prominent in the literature. The purpose of this study was to investigate several such relationships among college students of both sexes. While it is recognized that the restricted range of ability (and, to a lesser extent, of achievement) represented in the college population embarrases whatever relationships might hold in a population of greater range, it is asserted that it is beneficial to explore these variables in the very population utilized for a large share of psychological research in general and on $m$ in particular.

\section{METHOD}

The Ss in this study were 81 males and 85 females enrolled in the introductory psychology course at The Pennsylvania State University (PSU). Two-thirds of each sex were freshmen, the remainder were sophomores.

The Ss were asked, via instructions paralleling those of Noble (1952), to generate 1 -min continued associations to 31 stimulus nouns and adjectives selected from various sources to represent a wide range of frequency, concreteness, response hierarchy, and various connotative dimensions. The Ss were informed about the primary purpose of work which was to explore several dimensions of the stimulus words ("to learn about the associations given to various words") but were not informed about the interest in subject variables which is the focus of the present study. Correlational analyses were performed utilizing each S's mean $m$ for the 31 stimulus words and achievement and ability data available through the Office of Student Affairs Research (SAR) at PSU

The following measures were utilized:

(1) Scholastic Aptitude Test (SAT); Verbal, Mathematics, and Total Scores.

(2) English Placement Test (ENGL), a 120-item test designed by the PSU Department of English and SAR for placement in English courses; four subtests (spelling, vocabulary, punctuation, and grammar) and total score.

(3) Reading Ability and Comprehension Test developed by SAR and consisting of 30 items pertaining to 12 paragraphs; total score.

(4) Chemistry test designed for placement in chemistry courses by the PSU Department of Chemistry and SAR; total score.

(5) High school average expressed in terms of the conventional 4-point grading system.

(6) Predicted Grade Point Average (GPA), a SAR linear estimate, employing standard regression techniques, of a student's most probable third-term cumulative GPA in "Science" colleges and "NonScience" colleges, respectively.

(7) Actual GPA achieved for the term in which the study was conducted. These latter three GPAs are also expressed in terms of the 4-point grading system.

Statistical descriptions of the present samples are presented in Table 1. These data are closely congruent with SAR data available for all baccalaureate degree
Table 1

Descriptive Statistics Regarding Various Ability and Achievement Measures in a College Population

\begin{tabular}{|c|c|c|c|c|}
\hline \multirow{3}{*}{$\begin{array}{l}\text { Measure } \\
\text { SAT Verbal } \\
\text { SAT Math } \\
\text { SAT Total }\end{array}$} & \multicolumn{4}{|c|}{ Means and Standard Deviations } \\
\hline & \multicolumn{2}{|l|}{ Males } & \multicolumn{2}{|c|}{ Females } \\
\hline & $\begin{aligned} 525 & \pm \\
584 & \pm \\
1108 & \pm 11\end{aligned}$ & $\begin{array}{c}77 \\
71 \\
15\end{array}$ & $\begin{aligned} 546 & \pm \\
555 & \pm \\
1096 & \pm\end{aligned}$ & $\begin{array}{c}86 \\
81 \\
38\end{array} \quad * *$ \\
\hline $\begin{array}{l}\text { English: Spelling } \\
\text { English: Vocabulary } \\
\text { English: Punctuation } \\
\text { English: Grammar } \\
\text { English: Total }\end{array}$ & $\begin{array}{r}9.3 \pm \\
21.0 \pm \\
16.2 \pm \\
11.7 \pm \\
58.3 \pm\end{array}$ & $\begin{array}{r}3.4 \\
6.9 \\
4.2 \\
3.9 \\
13.9\end{array}$ & $\begin{array}{l}10.8 \pm \\
23.9 \pm \\
17.8 \pm \\
13.7 \pm \\
66.1 \pm\end{array}$ & $\begin{array}{c}3.8^{* *} \\
8.3^{*} \\
4.7^{*} \\
4.9^{* *} \\
18.5^{* *}\end{array}$ \\
\hline Reading Comprehension & $17.6 \pm$ & 3.8 & $18 \pm$ & 4.3 \\
\hline Chemistry & $20.8 \pm$ & 7.2 & $15.6 \pm$ & 8.5 \\
\hline High School Average & $2.9 \pm$ & .5 & $3.2 \pm$ & $.6 * *$ \\
\hline Predicted GPA, Non Science & $2.5 \pm$ & .3 & $2.6 \pm$ & .5 \\
\hline Predicted GPA, Science & $2.3 \pm$ & .3 & $2.4 \pm$ & .5 \\
\hline Cumulative GPA & $2.5 \pm$ & .7 & $2.7 \pm$ & .6 \\
\hline
\end{tabular}

$* p<.05, t$ test for uncorrelated means

$* * p<.01, t$ test for uncorrelated means 
students at PSU and support the picture of PSU female undergraduates showing greater spread on all variables, higher mean performance on verbal ability tests and high school grades and lower mean performance on mathematical aptitude measures.

RESULTS AND DISCUSSION

The results of the correlational analyses of $m$ and ability and achievement measures are summarized in Table 2 . Two findings seem at once apparent; there are a few significant, but modest, relationships between $m$ and indicants of verbal skills (vocabulary, punctuation, and total scores on English placement test), and these relationships hold for male Ss only. For females there are no significant correlates of $m$ among any of the achievement and ability variables studied, despite the females' consistently greater spread of scores on such measures and, hence, a concomitantly better opportunity for detection of correlates. A subsidiary finding of significantly $(p<.01)$ greater $m$ mean for females $(10.4 \pm 2.2$ vs $9.3 \pm 2.3$ for males) supports a similar finding reported by Matthews (1965).

Hypotheses regarding the differential relatedness in males and females of $m$ and the variables studied here can be tentatively entertained but seem within the realm of the extremely speculative considering the magnitude of the relatedness difference (none vs slight). With these reservations in mind, the data might be considered congruent with accumulating evidence regarding sex differences in cognitive style (Witkin, Lewis, Hertzman, Machover, Meissner, \& Wapner, 1954). Thus, the present results may partly reflect the greater field orientation (and hence stimulus dependence) of females, although such an interpretation obviously calls for more direct support.

Summarizing the results of this investigation, it appears that within a college population none (for females) or very little (for males) of the intersubject variance in associative response availability can be accounted for in terms of intellectual ability and achievement variables. Barring subsequent evidence to the contrary, the pragmatic value of these data may lie in the suggestion that it is appropriate to continue disregarding ability and achievement variables in exploring sources of individual differences in $m$ in a college population.

\section{REIERENCES}

BOUSEFIELD, W. A.. \& SAMBORSKI, G. The relationship between strength of values and the meaningfulness of value words. Journal of Personality. 1955, 23. 375-380.

CRAMIE. P. W'ord association. New York: Academic Press, 1968.

DAVIDS. A.. \& ERIKSON. C. W. The relation of manifest anxiety to association productivity and intellectual at tainment. Journal of Consulting Psychology, 1955 . 19, 219-222.

DIERING. G. Affective stimuli and disturbance of

Table 2

Relationships Between $m$ and Various Ability and Achievement Measures in a College Population

\begin{tabular}{lcc}
\hline Measure & Males & Females \\
\hline SAT Verbal & .10 & .14 \\
SAT Math & -.01 & .04 \\
SAT Total & .06 & .11 \\
English: Spelling & .17 & .01 \\
English: Vocabulary & $.24^{*}$ & .03 \\
English: Punctuation & $.23^{*}$ & -.05 \\
English: Grammar & .08 & -.04 \\
English: Total & $.26^{*}$ & -.01 \\
Reading Comprehension & .09 & -.01 \\
Chemistry & .05 & .07 \\
High School Average & .04 & .03 \\
Predicted GPA, Non Science & .09 & .10 \\
Predicted GPA, Science & .06 & .08 \\
Cumulative GPA & .08 & .02 \\
\hline
\end{tabular}

${ }^{*} p<.05$

thought processes. Journal of Consulting Psychology, 1963, 27, 338-343.

JOHNSON, R. C., \& LIM, D. Personality variables in associative production. Journal of General Psychology, 1964, 71, 349-350.

LAFFAL, J. Response faults in word association as a function of response entropy. Journal of Abnormal \& Social Psychology, 1955, 50, 265-270.

LESTER, J. R. Production of associative sequences in schizophrenic and chronic brain syndrome. Journal of Abnormal \& Social Psychology, 1960,60, 225-233.

MATTHEWS, W. A. The relation between association norms and word frequency. British Journal of Psychology, 1965, 56, 391-399.

MEDNICK, M. T., MEDNICK, S. A., \& JUNG, C. C. Continual association as a function of level of creativity and type of verbal stimulus. Journal of Abnormal \& Social Psychology, 1964, 69, 511-515.
NOBLE, C. E. An analysis of meaning. Psychological Review, 1952,59,421-430.

SHAPIRO, S. S. Word associations and meaningfulness values for grade-school-aged children. Psychological Reports, 1964, 15, 447-455.

VAN KREVELEN, A. Relationships between number of verbal associations to value words and subjective ratings of value. Proceedings of the Iowa Academy of Science, 1956, 63, 576-580.

WITKIN, H. A., LEWIS, H. B., HERTZMAN, M., MACHOVER, K., MEISSNER, P. B., \& WAPNER, S. Personality through perception. New York: Harper \& Row, 1954. NOTE

1. This project was supported by the Central Fund for Research of the Pennsylvania State University. Appreciation is expressed to Dr. Carl A. Lindsay of the Office of Student Affairs Research, The Pennsylvania State University, for making available the achievement and ability data.

\section{Retroactive inhibition and extended recall time'}

\author{
JOHN P. HOUSTON, University of Califor- \\ nia, Los Angeles, Calif. 90024
}

Subjects learned a single $A-B$ or successive $A \cdot B, A-C$ lists and were then tested for recall of the first-list materials after 1 week. In the MIMFR conditions a typical MMFR task was administered. In the extended conditions $S s$ were allowed I week to try to recall the materials. Both recall techniques produced significant RI. Ss in the extended conditions were able to recall a significant number of additional items during the week provided for recall. In agreement with the contention that competition has little effect upon recall, and in contrast to the assumption that extended recall might allow for the dissipation of competition effects, equal amounts of RI were obtained with the two recall techniques. 